\title{
Marcelo Marigo
}

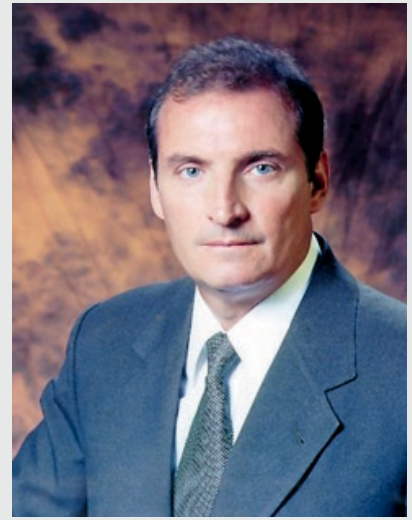

- Especialista, mestre e Doutor pela UNICAMP

- Presidente da Associação Brasileira de Ortodontia Lingual - ABOL

- Professor titular de Ortodontia da Universidade Vale do Rio Doce (UNIVALE)

- Reitor da Universidade Vale do Rio Doce (UNIVALE)

- Membro da Academia Mineira de Odontologia (cadeira $\left.n^{0} 6\right)$

- Coordenador do Curso de Especialização em Ortodontia da (UNIVALE)

A Ortodontia lingual, introduzida na década de 70 por Kraven Kurz, tem hoje seu crescimento exigido principalmente pela demanda dos pacientes adultos, cada vez em maior número nos consultórios de Ortodontia e intolerantes quanto ao desconforto estético imposto pelo aparelho convencional. Seu crescimento no cenário mundial é inegável com o mérito de vários profissionais preocupados em desvendarem as particularidades desta técnica. No Brasil, após uma introdução frustrada na década de 80 , observa-se o crescimento da quantidade de profissionais interessados em aprendê-la, forçados pela necessidade de oferecer novas possibilidades de tratamento a seus pacientes. É imprescindível, entretanto, a necessidade de um treinamento consistente nessa técnica a fim de que o profissional se habitue aos procedimentos de colagem indireta, além das dificuldades inerentes ao trabalho na superfície lingual, o que altera principalmente a relação entre o ponto de aplicação da força e o centro de resistência do dente. Sempre preocupado com o crescimento da Ortodontia lingual no país, para que seja realizado de forma consistente, trazendo benefícios para pacientes e profissionais, o Prof. Dr. Marcelo Marigo fundou a Associação Brasileira de Ortodontia Lingual (ABOL), sendo hoje o presidente desta Instituição. À frente da ABOL, o Prof. Dr. Marcelo Marigo promove cursos com profissionais mundialmente reconhecidos, dos quais tivemos a honra de participar, visando agregar os especialistas praticantes desta técnica e manter a qualidade da Ortodontia lingual no Brasil. Como membros da ABOL, é com imensa satisfação, portanto, que apresentamos o Prof. Dr. Marcelo Marigo, Reitor da Universidade do Vale do Rio Doce para falar deste assunto, tão importante para nós, diante da realidade da Ortodontia atual.

Silvia Augusta Braga Reis - Profa. Assistente de Ortodontia da Universidade Metodista de São Paulo; Coordenadora do $1^{\circ}$ Curso Brasileiro de Tratamento Ortodôntico em Adultos

Liliana Ávila Maltagliati-Profa. Titular de Ortodontia da Universidade Metodista de São Paulo; Coordenadora do curso de Especialização em Ortodontia da Universidade Metodista de São Paulo; Coordenadora do $1^{\circ}$ Curso Brasileiro de Tratamento Ortodôntico em Adultos 
1) Qual é a melhor indicação para o uso da Técnica Lingual na Ortodontia contemporânea? Kurt Faltin Jr.

Segundo Didier Filion e outros nomes de destaque na técnica, todos os arcos podem ser colados, todas as más oclusões podem ser tratadas. Porém em minha prática, mesmo que apenas de 1998 até agora, quanto à Ortodontia lingual, vejo algumas restrições, não técnicas, contudo de praticidade de aplicações. Como a técnica necessita de um período de adaptações, entendo que a criança deva estar excluída de nosso quadro de indicações. A melhor indicação estaria realmente, direcionada àquele paciente adulto que não aceita o desconforto visual metálico dos braquetes e nem mesmo os mais discretos, como os de cerâmica. Precisamos de muita motivação, e a motivação estética vem a compensar os desconfortos de adaptação ao aparelho lingual.

\section{2) Quais são os cuidados principais que de-} veremos tomar no uso dessa técnica relacionados com a biomecânica em Ortodontia? Kurt Faltin Jr.

Os cuidados e preocupações são as mesmas das técnicas convencionais, ou seja, atenção no seu diagnóstico e planejamento, ancoragem, etc. Porém, temos uma resposta negativa nos casos de extrações, que se não tivermos o cuidado de neutralizarmos, o efeito "bowing", que abre a mordida, já que a maior dificuldade da técnica é o controle e fechamento da mordida aberta. Uma atenção especial deve ser dada à ancoragem na mecânica lingual, que quando comparada à vestibular, há maior perda de ancoragem.

\section{3) Existem contra-indicações para o seu uso?} Kurt Faltin Jr.

Como toda técnica podemos ter contra-indicações ou mesmo limitações de resultados, principalmente, repito, nos casos de mordida aberta. Tenho uma preocupação quanto à biocompatibilidade dos braquetes linguais. São mais volu- mosos e provavelmente sofrem mais corrosões pela lingual e ainda estão mais próximos aos tecidos gengivais, podendo causar reações de hipersensibilidade ao metal desprendido pelo processo de corrosão. No meu conhecimento ainda não temos braquetes lingual "níquel free". Dependendo da sensibilidade do paciente a esses metais, a técnica estaria contra indicada. Atualmente desenvolvo pesquisa nesse sentido.

4) Na UERJ, temos proporcionado experiência com Ortodontia Lingual aos nossos alunos de especialização após um ano de curso (em horário integral) e mesmo assim eles têm tido muitas dificuldades com a técnica. Ao seu ver, como deveria ser introduzido o ensino da Ortodontia Lingual nos cursos de especialização? Seria conveniente uma experiência prévia de alguns anos com Ortodontia Vestibular? Marco Antônio Almeida

Fico muito satisfeito em saber que faz parte do projeto pedagógico de seu curso de especialização a Ortodontia lingual. Coordeno aqui na Universidade, o curso Latu Sensu em Ortodontia e também tenho a Ortodontia lingual como parte de nosso projeto. Entendo que este é o caminho, ou seja, introduzir a técnica aos alunos de especialização com responsabilidade e supervisão capacitada. A oportunidade dos alunos iniciarem a técnica numa instituição séria é pouco comum, sendo assim, independentemente das dificuldades encontradas pelo iniciante, entendo que estamos no caminho certo.

5) No Rio de Janeiro, profissionais se intitulam especialistas em Ortodontia Lingual através de cursos por correspondência, dando uma conotação mais "marqueteira" do que científica à técnica. Tal fato não poderia induzir ao segundo fracasso da Ortodontia Lingual, como ocorreu nos anos 80? Marco Antônio Almeida

Penso que a Ortodontia anda meio banalizada 
por pessoas que não são qualificadas e usam o marketing enganoso para se promoverem. A técnica lingual não foge disso. Essa é a razão principal da necessidade de fortalecermos a Associação Brasileira de Ortodontia Lingual. Para que esses "profissionais" possam ser alertados quanto à necessidade de maior consciência e prática da técnica com qualificação. Estes profissionais citados pelo colega estarão, sem dúvida, fadados ao insucesso, porque a técnica não permite falta de domínio, os resultados serão desastrosos. E concordo sim, se os que dedicam com qualificação técnica não desenvolverem projetos de conscientização ampla, podemos estar comprometidos como no passado.

6) No contexto da Ortodontia no Brasil, qual a expectativa de crescimento da Ortodontia Lingual? Leopoldino Capelozza Filho

Penso que temos uma perspectiva fabulosa com crescimento da técnica no país e no mundo. Tive a oportunidade de participar de congressos da Sociedade Européia de Ortodontia Lingual em Bruxelas e Berlim e pude notar claramente este crescimento. Principalmente nos trabalhos científicos, quando passaram a ser mais profundos e sérios. Este ano, em junho ele será em Barcelona e tenho absoluta certeza que grandes avanços serão o destaque nesse evento. Contudo, estaremos dependentes de ações em nosso país para que não aconteça o relatado pela pergunta do colega Marco Antônio Almeida.

7) Olhando numa perspectiva bem ampla, qual seria a maior vantagem e a maior desvantagem da Ortodontia lingual? Leopoldino Capelozza Filho

Sem dúvida, a questão estética é a maior vantagem da técnica. Se submeter a um tratamento ortodôntico sem o "desconforto" do visual metálico é o anseio de diversos pacientes adultos. Entre as maiores desvantagens poderíamos enumerar o desconforto da adaptação, o custo e as dificuldades técnicas.
8) Em sua opinião, qual é a melhor forma para um ortodontista iniciar seu aprendizado na técnica lingual? Luis Gonzaga Gandini Jr.

Conforme relatei na questão do Prof. Marco Antonio Almeida, entendo que já poderíamos estar introduzindo o interessado à técnica durante os cursos de especialização. E, aqueles que já possuem o título, naturalmente devem investir em cursos com maior carga horária e se possível nos cursos onde tenha conteúdo de typodont (tradicional), quando o profissional poderia estar acompanhando todo o desenvolvimento do trabalho. A Associação Brasileira de Ortodontia Lingual estará oferecendo um curso desse nível no segundo semestre deste ano.

9) Quais as razões que o Sr. encontra para justificar a um profissional a necessidade de que ele caminhe na direção da Técnica Lingual? Luis Gonzaga Gandini Jr.

Penso que a maior necessidade parte do próprio paciente. Hoje já existe uma exigência estética maior por parte do paciente adulto, que já é maioria em nossas clínicas. A Técnica Lingual é uma alternativa de um tratamento ortodôntico estético e na competitividade atual a técnica lingual passa a ser um diferencial...

10) O Sr. considera que os princípios biomecânicos e os tipos de movimentos obtidos, bem como tendências dos efeitos colaterais, para trabalhar-se por vestibular e lingual são semelhantes? Exemplifique. Luis Gonzaga Gandini Jr.

A busca é a mesma, ou seja, aproximarmos ao máximo da normalidade. A biomecânica da Técnica Lingual tem algumas vantagens em relação à técnica vestibular. Devemos levar sempre em conta o centro de resistência (CR) do dente e o local da aplicação das forças, bem como as distâncias inter braquetes. $\mathrm{Na}$ técnica lingual normalmente os braquetes estão posicionados mais próximo do $\mathrm{CR}$ do dente, sendo assim existem diferenças biomecânicas consideráveis 
e acredito em melhores resultados biológicos utilizando forças mais leves na Técnica Lingual. Como já relatamos na pergunta do professor Kurt há efeitos colaterais que precisam um maior controle da aplicação dessas forças na Técnica Lingual.

11) Em termos de excelência de resultados e dificuldades para atingí-los faça um comparativo entre a Técnica Lingual e a vestibular. Luis Gonzaga Gandini Jr.

Não vejo distinção das técnicas no que se diz respeito à excelência dos resultados, ambas dependem de fatores já conhecidos: a colaboração do paciente, as dificuldades inerentes ao próprio caso, as reações biológicas individuais e por fim a qualidade técnica do profissional. Quanto as dificuldades, considero sem dúvida a técnica lingual com um grau bem superior à vestibular.

12) Quais são os fatores mais importantes a serem controlados para se atingirem resultados finais de excelência? Luis Gonzaga Gandini Jr.

Principalmente o fator que precede o tratamento - a fase laboratorial. É fundamental para bons resultados que tenhamos uma precisão nos passos laboratoriais. Outro fator que acrescentaria é o controle de ancoragem.
Kurt Faltin Jr.

- Presidente da Associação Brasileira de Ortodontia.

- Formado pela PUC de Campinas.

- Pós-graduado em Ortopedia maxilar pela Universidade de Bonn - Alemanha.

- Doutorado (Doutor em Medicina Dentística) em Ortopedia pela Universidade de Bonn - Alemanha.

- Professor Titular da disciplina de Ortodontia da UNIP.

- Coordenador do Curso de Especialização em Ortodontia da UNIP.

- Pertence a APCD, SPO, SPrO, AAO, Sociedade Brasileira de Reabilitação Oral, ABOM, Sociedade Alemã de Ortopedia Maxilar, Foundation Ort. Research.

- Escreveu vários artigos no Brasil e Exterior, além de capítulos em diversos livros.

- Ministrador de Conferências e cursos no Brasil e no Exterior.

\section{Leopoldino Capelozza Filho}

- Professor Assistente Doutor da Faculdade de Odontologia de Bauru da Universidade de São Paulo.

- Responsável pelo Setor de Ortodontia do Hospital de Reabilitação de Anomalias Craniofaciais da Universidade de São Paulo, em Bauru-SP.

\section{Luiz Gonzaga Gandini Jr.}

- Professor Assistente Doutor do Departamento de Clínica Infantil- Disciplina de Ortodontia, na Universidade Estadual Paulista - UNESP, Campus Araraquara.

- Pós-graduado em Odontologia, nível de mestrado e doutorado, pela Faculdade de Odontologia da Universidade Estadual Paulista - UNESP, campus de Araraquara.

- Prof. Adjunto clínico do departamento de Ortodontia da Baylor College of Dentristy - Dallas/USA.

- Pós-doutorado na Baylor College of Dentristy - Dallas/USA.

\section{Marco Antonio Almeida}

- Prof. Titular de Ortodontia UERJ

- Research Fellow Universidade da Carolina do Norte

- Mestre em Ortodontia UFRJ

- Livre Docente em Ortodontia UERJ

- Coordenador do Curso de Mestrado em Ortodontia UERJ 